\title{
EVALUATION OF GERMICIDAL UV-C LIGHT FOR SURFACE DISINFECTION IN A TERTIARY CARE HOSPITAL
}

\author{
Qanita Fahim, Nasir Uddin, Najam Ul Hassan, Nargis Sabir*, Anam Tariq, Ayesha Bashir, Sarmad Ahmad** \\ Combined Military Hospital Lahore/National University of Medical Sciences (NUMS) Pakistan, *Combined Military Hospital Nowshera/National University of \\ Medical Sciences (NUMS) Pakistan, ${ }^{* * N U S T ~ C o l l e g e ~ o f ~ E l e c t r i c a l ~ a n d ~ M e c h a n i c a l ~ E n g i n e e r i n g, ~ R a w a l p i n d i ~ P a k i s t a n ~}$
}

\begin{abstract}
Objective: To check the efficacy of 36-Watt Ultraviolet-C tube light, in terms of distance and time against medically important microorganisms (Staphylococcus aureus, Escherichia coli, Pseudomonas aeroginosa, Candida albicans and Aspergillus species).

Study Design: Quasi-experimental study.

Place and Duration of Study: Pathology department, Combined Military Hospital, Lahore Pakistan, from Jun to Sep 2020.

Methodology: ATCC control organisms of above mentioned bacteria, yeasts, and fungi were exposed to ultraviolet-C light for different times and distances to ascertain its germicidal effect. Two methods were selected, one in which micro-organisms inoculated plates were exposed to ultraviolet-C light and second in which McFarland suspensions of microorganisms were exposed before inoculation. Both the methods were compared. Observations were noted down after repeated performance of both the procedures.

Results: An exposure time of 15 minutes, mean \pm SD $(13.8 \pm 10.1)$ at 1-foot distance was proved ideal for all the tested bacteria, but yeasts and fungi required $>30$ minutes, mean \pm SD $(17.5 \pm 13.5)$ to be killed. Moreover, distance and time of exposure were found out to be directly proportional irrespective of microbial load. Greater the distance longer the ultraviolet $\mathrm{C}$ exposure was required.

Conclusion: Ultrviolet-C light 36-Watt can have efficient inactivation of bacterial, fungal and archaeal species up to 6 feet for >30 minutes exposure time. Ultraviolet-C light disinfection is best for areas like closed rooms, operation theatres, PCR Labs, and bio-safety cabinets keeping bio-safety guidelines in view.
\end{abstract}

Keywords: Disinfection, Microorganisms, Ultraviolet-C light.

This is an Open Access article distributed under the terms of the Creative Commons Attribution License (https://creativecommons.org/licenses/by-nc/4.0/), which permits unrestricted use, distribution, and reproduction in any medium, provided the original work is properly cited.

\section{INTRODUCTION}

By the end of year 2019, an outbreak of novel human corona virus leading to serious pneumonia emerged in Peoples Republic of China, City of Wuhan, Hubei province, that consequently became a global pandemic ${ }^{1}$. Molecular specialists all over the world endeavored to sequence its genome (29,903 nucleotides). It was identified as a novel corona virus (2019-nCOV) ${ }^{1}$. It is the seventh member of the corona virus family. It infects humans and has been named by the International Committee on Taxonomy of viruses as "SARSCoV-2". On the $11^{\text {th }}$ of February 2020, the disease caused by this virus was named by the World Health Organization (WHO) as "Corona Virus Disease 19 (COVID 19)"2,3.

In the wake of ongoing pandemic a continuous search for disinfectants to neutralize surfaces and the environment, infected with corona virus has led to the discovery of using ultraviolet C (UVC) light for the purpose. UVC light has long been known for its antimicrobial effects in water, food items, and ventilator

Correspondence: Dr Qanita Fahim, Associate Professor, Department of Microbiology, Combined Military Hospital, Lahore Pakistan

Received: 17 Dec 2020; revised received: 26 Feb 2021; accepted: 08 Mar 2021 ducts 4 . Many handy devices containing UVC light are available in the markets. Many manufacturers claim the sporicidal/viricidil activity of these products. During COVID-19 pandemic, hospitals are in search of a product that can neutralize or clean the hospital environment with efficiency and consistency against viruses and bacteria. Many studies have evaluated the role of UVC light to reduce the bioburden of Acinetobacter, VRE, MRSA, Ebola and Clostridium difficile in hospital rooms ${ }^{5-7}$.

Keeping above in view, an in-house UVC disinfection device was designed (fig-1) by a member of our study group from Military Engineers Corp Lahore. It was desired to ascertain its efficiency and potential utility as a disinfectant of surfaces in the settings of health care facilities. Simultaneously, a quasi- experimental study was planned in Microbiology Department, $\mathrm{CMH}$ Lahore to ascertain the germicidal effect of UVC light against commonly encountered bacteria, yeasts, and fungi. The concept of this study was based on a hypothesis that if UVC light can kill most of the medically important microorganisms, then it will have a viricidal effect as well. Hence, it can be utilized to disinfect the environment of closed rooms, operation theatres (OT), Laboratory departments especially PCR 
rooms, hospital ITCs and dental procedure rooms against corona virus.

This study was aimed to check the efficacy of 36-Watt UVC tube light, in terms of distance and time against medically important microorganisms, (Staphylococcus aureus, Escherichia coli, Pseudomonas aeroginosa, Candida albicans, and Aspergillus species).

\section{METHODOLOGY}

This quasi experimental study was conducted at Pathology department, Combined Military Hospital (CMH) Lahore Pakistan, from June to September 2020 after approval from Research Review Board, Combined Military Hospital Lahore (RRB ltr no. 236/2020). All informations in the study were kept confidential. Meanwhile subject Performa had been distributed to health care workers (HCWs) as a pilot project.

A UVC tube, (TUV 36W ISL, Phillips, Holland), UVC radiation 15 watts, 48 inches long, 1 inch in diameter, emitting short wave UV radiation of $253.7 \mathrm{~nm}$ was used in the study. In this study, three bacterial (Escherichia coli, Staphylococcus aureus, Pseudomonas aeroginosa), one fungal (Aspergillus $s p$ ) and one archaeal (Candida albicans) strains were selected. American Type Culture Collection (ATCC) strains selected, were Escherichia coli ATCC 25922, Staphylococcus aureus ATCC 25923, Pseudomonas aeroginosa ATCC 27853, Candida albicans ATCC 10231, and Aspergillus sp ${ }^{8,9}$. All bacteria were grown in nutrient broth and subcultured on blood agar and Mac Conkey agar. Yeast and fungus were subcultured on Sabouraud dextrose agar. The first four were incubated for 18-24 hours at $35 \pm 20 \mathrm{C}$ in ambient air. Aspergillus sp was incubated at $220 \mathrm{C}$ for 6-7 days for spores to mature. Later, spores were suspended in normal saline for UVC light exposure9.

\section{Method-1}

A suspension of each of above-mentioned microbes was made, and the opacity was adjusted to $0.5 \mathrm{Mc}$ Farland standards. After inoculation of $100 \mu$ l of each bacterial suspension on MacConkey agar and fungal and yeast on Sabouraud agar plates (Oxoid, UK) (Preexposure control plates), the Same Mc Farland suspensions were then exposed to UV-C light, which was horizontally placed on a table for 15, 20 and 30 minutes at a constant distance i.e., 1 foot. $100 \mu \mathrm{I}$ of these suspensions of bacteria after each exposure to UVC light were then subcultured on appropriate media and incubated as mentioned above. Suspensions of Aspergillussp were incubated at $22^{\circ} \mathrm{C}$ for 48 hours. This procedure was repeated and again with each increment of distance till the final exposure of suspensions at 6 feet for
15, 20 and 30 minutes were done. This method was less labor intensive and cheap.

\section{Method-2}

$100 \mu 1$ of each of bacterial suspension was inoculated on 19 plates of MacConkey agar. One (pre exposure control plate) was incubated at standard temp and time as Mc Farland control. Rest were placed vertically facing towards UVC light with lids off at distances of 1-6 feet, exposed for 15, 20 and 30 minutes and incubated at standard time and temperature. Colony count was noted down in the form of colony-forming units per milli litter CFU/ml. Candida albicans and Aspergillussp. Were inoculated on Sabouraud agar and after exposure to UVC light, plates were incubated as mentioned above. This method was labour intensive and required 19 plates of MacConkey agar for each organism.

Mc Farland Control: 0.5Mc Farland means a viable colony count equal to 1.5 x $108 \mathrm{CFU} / \mathrm{ml}$. A suspension of each of a known microbe was made and opacity was adjusted to $0.5 \mathrm{McF}$ arland standards. $0.1 \mu \mathrm{l}$ of this suspension was added to $9.9 \mathrm{ml}$ of distilled water (DW) making 1/100 dilution (Dilution 1) and further $0.1 \mu$ l of dilution 1 was added to $9.9 \mathrm{ml} \mathrm{DW}$ to make a dilution of $1 / 10000.100 \mu \mathrm{l}$ of second dilution when inoculated on MacConkey agar (Oxoid, UK) and incubated for 24 hours yielded growth of $10 \mathrm{CFU}$, confirming its fitness ${ }^{10}$. UVC light of 36 Watt, (Phillips, Holland) of Microbiological safety cabinet (Technico Scientific supply), class II was taken as "Gold Standard". Results were comparable with "Gold Standard" UVC light.

Data was analyzed using the ratio of viable count of respective organisms before and after exposure to UVC light. $100 \mu 1$ of all suspensions adjusted to 0.5 McFarland standard after dilutions $(1 / 100,1 / 10,000)$ were sub cultured on MacConkey agar for quality, growth, and growth condition check and incubated for 18-24 hrs at $35 \pm 20 \mathrm{C}$. A colony count of 10 was taken as an indicator of good quality McFarland. Finally, all the observations were noted down after repeated performance of both the procedures and getting the same results.

\section{RESULTS}

$100 \mu 1$ of initial suspension of Staphylococcus aureus when inoculated on MacConkey agar and blood agar yielded growth of approximately $107 \mathrm{CFU} / \mathrm{ml}$ of organism and when exposed to UVC light for 15 minutes at a distance of 1 foot yielded no growth and subsequently at 2, 3, 4, 5 and 6 feet yielded growth of nil, 3, 3, 4 and $10 \mathrm{CFU} / \mathrm{ml}$ or (six Log10 reduction) i.e., from 107 to $101 \mathrm{CFU} / \mathrm{ml}$ (fig-2). Similar results were obtained 
against Pseudomonas aeruginosa and Escherichia coli when $100 \mu \mathrm{l}$ of initial suspension of these organisms were inoculated on blood agar and MacConkey agar yielded approximately $107 \mathrm{CFU} / \mathrm{ml}$ of organisms and when exposed to UVC light for 15 minutes at a distance of 1 foot yielded no growth and at 2, 3, 4, 5 and 6 feet yielded growth of nil, 15, 18, 20 and $35 \mathrm{CFU} / \mathrm{ml}$ (six Log-10 reduction) i.e from 107 reduced to101 $\mathrm{CFU} / \mathrm{ml}$ (table-I).
Dose of Ultraviolet-C required to kill these microorganisms has been calculated and shown in (table-II).

\section{DISCUSSION}

Primarily SARS-CoV-2 was transmitted to humans through bat according to one of the study while other suggested transmission through snakes, turtles and pangolins ${ }^{1,11}$. However, a well known mode of transmission of SARS-CoV-2 infection among commu-

Table-I: Colony counts of micro-organisms on pre-exposure (control plate) and post-exposure MacConkey, and Sabouraud agar plates according to Method-2.

\begin{tabular}{|c|c|c|c|c|c|c|c|c|c|}
\hline \multirow[b]{2}{*}{ Organisms } & \multirow[b]{2}{*}{$\begin{array}{l}\text { Time } \\
(\mathrm{min})\end{array}$} & \multirow{2}{*}{$\begin{array}{c}\text { CFU/ml } \\
\text { Control } \\
\text { (Pre-exposure) } \\
\end{array}$} & \multicolumn{6}{|c|}{ Growth of CFU/ $\mathrm{ml}$ at Distances in feet } & \multirow{2}{*}{$\begin{array}{c}\log 10 \\
\text { Reduction }\end{array}$} \\
\hline & & & I ft & $2 \mathrm{ft}$ & $3 \mathrm{ft}$ & $4 \mathrm{ft}$ & $5 \mathrm{ft}$ & $6 \mathrm{ft}$ & \\
\hline \multicolumn{10}{|c|}{ Staphylococcus Aureus } \\
\hline & 15 & 10 & Nil & Nil & 3 & 3 & 4 & 10 & $6 \log 10$ \\
\hline & 20 & & Nil & Nil & 01 & 01 & 02 & 08 & $6 \log 10$ \\
\hline & 30 & & NIL & Nil & Nil & Nil & Nil & 05 & $6 \log 10$ \\
\hline \multicolumn{10}{|c|}{ E coli and Pseudomonas Aeruginosa } \\
\hline & 15 & 11 & Nil & Nil & 15 & 18 & 20 & 35 & $6 \log 10$ \\
\hline & 20 & & Nil & Nil & 10 & 12 & 18 & 30 & $6 \log 10$ \\
\hline & 30 & & Nil & Nil & Nil & Nil & 10 & 25 & $6 \log 10$ \\
\hline \multicolumn{10}{|c|}{ Candida Albicans } \\
\hline & 15 & 10 & Nil & Nil & 7 & 10 & 19 & 22 & $6 \log 10$ \\
\hline & 20 & & Nil & Nil & 5 & 8 & 15 & 27 & $6 \log 10$ \\
\hline & 30 & & Nil & Nil & Nil & 6 & 18 & 25 & $6 \log 10$ \\
\hline \multicolumn{10}{|c|}{ *Aspergillus species (approx CFU/ml) } \\
\hline & 15 & 13 & 63 & 70 & 77 & 82 & 84 & 90 & $6 \log 10$ \\
\hline & 20 & & 08 & 10 & 17 & 30 & 32 & 35 & $6 \log 10$ \\
\hline & 30 & & Nil & Nil & Nil & 12 & 17 & 28 & $6 \log 10$ \\
\hline
\end{tabular}

${ }^{*}$ Aspergillus sp;CFU/ml were roughly counted as one can only make subjective assessment in this case.

$100 \mu 1$ of initial suspension of Candida albicans, when inoculated on Sabouraud agar yielded approximately $107 \mathrm{CFU} / \mathrm{ml}$ and UVC light post exposure of 15 minutes at a distance of 1 foot yielded no growth and at 2, 3, 4, 5 and 6 feet yielded growth of nil, 7, 10, 19, and $22 \mathrm{CFU} / \mathrm{ml}$ (six $\log 10$ reduction) i.e., from 107 to $101 \mathrm{CFU} / \mathrm{ml}$ (table-I). A similar reduction was observed in both. $100 \mu \mathrm{l}$ of initial suspension of Aspergillus $\mathrm{sp}$, when inoculated on Sabouraud agar yielded approximately $107 \mathrm{CFU} / \mathrm{ml}$ and UVC light post-exposure of 15 minutes at a distance of 1 foot yielded no growth and at 2, 3, 4, 5 and 6 feet yielded growth $<6$ logs (six Log10 reduction). Similar reduction was observed in both the methods (table-I). $100 \mu \mathrm{l}$ of initial suspensions in all the tested microorganisms had yielded $107 \mathrm{CFU} /$ $\mathrm{ml}$ but post-exposure of 15 minutes up to a distance of 1 foot from UVC device had given no growth of these microorganisms. However, UVC from the device was effective up to a distance of 6 feet by giving substantial growth reduction in these microorganisms (fig-1). nity is through respiratory droplets formation by infected persons. Other known potential sources of transmi-

Table-II: Dose calculation of ultraviolet $C$ light.

\begin{tabular}{|c|}
\hline $\begin{array}{c}\text { Watts } x \text { Intensity Factor }=\mu W s / \mathrm{cm}^{2} \text { or } W s=J \text { (Joules) or } \\
\mu \mathrm{J} / \mathrm{cm}^{2}\end{array}$ \\
\hline UV Dose $=$ UV density $x$ time in sec \\
\hline UV Dose / UV Density $=$ Time in sec \\
\hline UV Density is multiplied by area which is $\pi r^{2}$ \\
\hline$\Pi=3.14 \times \mathrm{r} 2(\mathrm{r}$ is radius in meter $)$ \\
\hline $\begin{array}{c}\text { UV Dose required for Staphylococcus Aureus is } 5786 \\
\mu \mathrm{Ws} / \mathrm{cm}^{2} \text { or } \mu \mathrm{J} / \mathrm{cm}^{2} \text { as per American air and } \\
\text { water company } 11\end{array}$ \\
\hline $\begin{array}{c}5786 \times 4 \times 3.14 \times 1 / 15=5526.4 / 60=81 \mathrm{~min} \\
\text { for } 1 \text { meter distance Or }\end{array}$ \\
\hline $\begin{array}{c}5786 \times 43.14 \times 0.5 / 15=2763.2 / 60=40 \mathrm{~min} \\
\text { for } 1 / 2 \text { meter distance }\end{array}$ \\
\hline $\begin{array}{c}5786 \times 4 \times 3.14 \times 0.25 / 15=1381.6 / 60=20 \mathrm{~min} \\
\text { for } 1 / 4 \text { of meter }\end{array}$ \\
\hline
\end{tabular}

ssion are contaminated surfaces made up of metal, glass and plastic. The virus can survive for 2-3 days on 
these surfaces ${ }^{1,11}$. As most of the surfaces frequently touched by health care workers in the hospitals are made up of these materials. There is a potential hazard of contracting coronavirus via touching these surfaces. It has been shown that the virus survives better at 30 $50 \%$ humidity for 2 hours to 9 days at room temperature in a closed room environment and surfaces ${ }^{12}$.

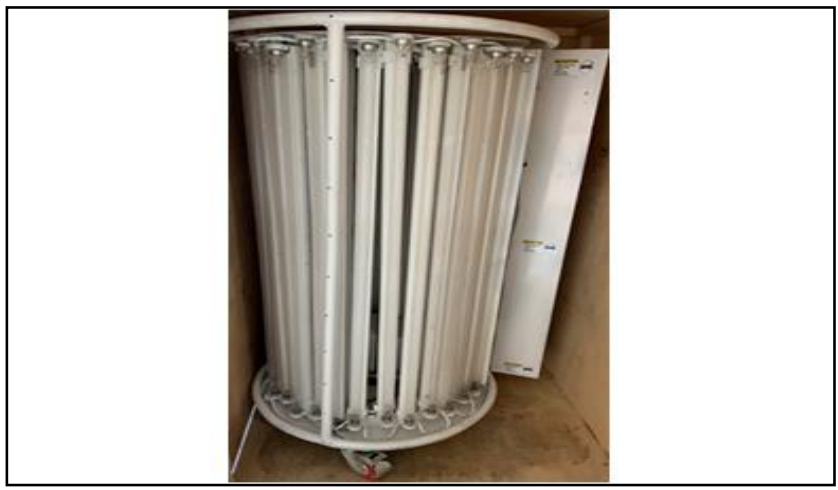

Figure-1: Ultraviolet-C emitting device, perceived and designed by engineer Najam Ul Hassan.

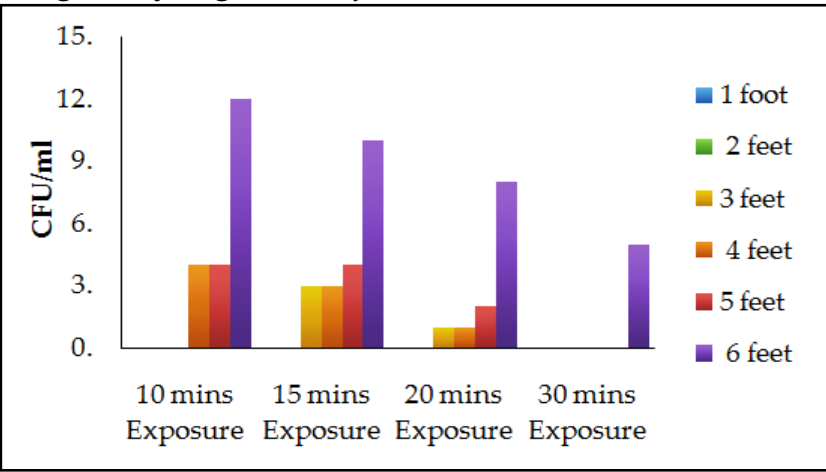

Figure-2: Number of $\mathrm{CFU} / \mathrm{ml}$ of staphylococcus aureus against exposure time.

In corona virus pandemic, humanity is in search of suitable treatment and prevention. The additional thing that can limit its spread among people is a dry, clean and disinfected environment ${ }^{4,12,13}$. Many methods of disinfection have been suggested by CDC and other professional bodies for environmental disinfection. These include natural ventilation having minimum of six air changes per hour (ACH), use of chlorine and alcohol based disinfectants through spray or defogger for 35-45 minutes, HEPA filters 13/14 with minimum $12 \mathrm{ACH}$ and Ultraviolet germicidal irradiation (UVGI) $4,12,13$. Although preventive strategies like vaccines prove promising yet practically an effective vaccine and vaccination of masses is still in clinical trials and may require $8-9$ months. Finally, disinfection is the last resort which is of paramount importance.
UV irradiation is divided into three different spectral areas UV, UVA, UVB and UVC having a wavelength of 100-200, 315-400, 280-315 and 200-280 $\mathrm{nm}^{14}$. The best wave length absorbed by nucleic acid of microorganisms is UVC15, it ranges from $250-270 \mathrm{~nm}$ and damages the nucleic acid (DNA, RNA) of the microorganism completely ${ }^{15,16}$. The process is called dimerization of pyrimidine molecules which makes replication of nuclear material of microorganisms impossible ${ }^{17}$.

Germicidal effect of UV radiation has been known for decades. The researchers, however, have been reluctant to use it for disinfection of hospital environment. Studies have explicitly shown its high germicidal capacity against hospital contained resistant bacteria/viruses $^{12,13,15,16}$. It kills rapidly multiplying microorganisms in the indoor environment. Moreover, it reduces the bioburden of airborne pathogens especially, those resting on inanimate surfaces.

We tried a simple model to find out whether UVC light could be used for inactivation of microbes lying on the surfaces frequently encountering health care workers or not and whether it had a good germicidal activity or not. Our simple quantitative assessment proved the use of UVC light having $253.7 \mathrm{~nm}$ wavelength of 36 Watts effective against common hospital microbes.

The UVC light emitting device was mounted on a circular frame with tyres to roll on and was remote control operated. It moved around in the room on its own. If command were given to stand by each surface for almost 20 minutes, it would definitely decontaminate the surface by killing all vegetative bacteria present on it (fig-1). Its germicidal effect was best achieved $(100 \%)$ at a distance of 1 foot for 20 minutes. it can still kill all bacterial forms to maximum (i.e., 95-98\% ) with increase in exposure time (i.e., 30 minutes) up to a distance of 6 feet. Fungal, and yeast forms were also reduced. However, it requires an exposure of $>30$ minutes as it is evident from our results (table-I). Similar findings have been described by Adebiyi et al that yeast and fungi require greater exposure time and have $0 \%$ survival rate at longer exposures to UVC light ${ }^{18}$. G katara and coworkers also proved an exposure time of 40 minutes up to 8 feet distance ${ }^{19}$.

It has been observed that distance and exposure time both are directly proportional to each other i.e., with smaller distance lesser exposure time was required and with greater distance longer exposure time is required; Distance (D) is directly proportional to time 
of exposure $(\mathrm{T})$ provided that area is thoroughly exposed without any object in-between that shadows (fig$2)^{20}$. Moreover, microbial bio-load also proved to have no direct effect on UVC exposure time i.e., greater load requires same exposure times provided required dose of UVC light has been given. According to Mahida and Linblad et al, UVC energy of $12000 \mathrm{~m} \mathrm{Ws} / \mathrm{cm}^{2}$ is required to kill vegetative bacteria but UVC energy dose of $22000 \mu \mathrm{Ws} / \mathrm{cm}^{2}$ is required against all pathogens ${ }^{12,20}$.

In our device, (fig-1) UVC lights were mounted/ fixed in vertical position on the device, in that case light waves would have fallen from sideways, which would have hidden half of tubes behind the working bench in the laboratory, had it been possible to change the position from vertical to horizontal larger area of working benches would have been exposed and disinfected the lab working benches fully.

\section{RECOMMENDATIONS}

- UVC fixed devices can be easily used to disinfect environment and surfaces of hospital wards, operation theatres, laboratory rooms, ICUs, ITCs, Corona PCR rooms. It should be remote control operated and rooms and areas to be decontaminated should be vacated first before it starts functioning.

- Device should be operated at appropriate distance. Adequate exposure time should be allowed for contact on the surface to be disinfected.

- Standard safety guidelines should be kept in mind before its use as UVC is known for its carcinogenic effect on human eyes and skin.

Note: UVC light disinfection is best for areas like closed rooms, operation theatres, PCR Labs and biosafety cabinets.

Warning: National Institute of Occupational safety and Health (NIOSH) recommends that the time of exposure for humans to an intensity of UVC 100 $\mu$ watts $/ \mathrm{cm}^{2}$ at wave length 254 nanometers should not exceed 1 minute.

\section{ACKNOWLEDGEMENT}

We acknowledge efforts of Shakil Ahmed who continuously have properly helped in laboratory work up.

\section{CONCLUSION}

UVC light 36 Watt can have efficient inactivation of vegetative microorganisms up to 6 feet if exposure time is $>30$ minutes. This Ultraviolet-C light disinfection experience can be reciprocated against corona virus but needs further evaluation.

\section{CONFLICT OF INTEREST}

This study has no conflict of interest to be declared by any author.

\section{REFERENCES}

1. Kakakhel MA, Wu F, Khan TA, Feng H, Hassan G, Anwar Z, et al. The first two months of epidemiological study of COVID-19, related public health preparedness, and response to the ongoing epidemic in Pakistan. New Microb New Infect 2020; 37(3): 100734-38.

2. Gorbalenya AE, Baker S C, Baric RS, de Groot RJ, Drosten C, Gulyaeva AA, et al. The species Sever acute respiratory syndrome-related coronavirus: classifying 2019-nCoV and naming it SARS-CoV-2. Nature Microbiol 2020; 5 (4): 536-44.

3. World Health Organization (WHO).Getting your work place ready for COVID-19. [Internet] Available from: https//www. who.int/docs/default-source/coronavirus/getting ready for COVID 19. pdf. [Acessed on March 2020].

4. Boyce JM, Havill NL, Moore BA. Terminal decontamination of patient rooms using an automated mobile UV light unit. Infect Control Hosp Epidemiol 2011; 32(8): 737-42.

5. Anderson DJ, Gergen MF, Smathers E, Sexton DJ, Chen LF, Weber DJ, et al. Decontamination of targeted pathogens from patient rooms using an automated ultraviolet-C-emitting device. Infect Control Hosp Epidemiol 2013; 34(5): 466-71.

6. Narita K, Asano K, Naito K, Morimoto Y, Igarashi T. Ultraviolet $\mathrm{C}$ light with wavelength of $222 \mathrm{~nm}$ inactivates a wide spectrum of microbial pathogens. J Hosp Infect 2020; 105(3): 459-67.

7. Nerandzic MM, Cadnum JL, Eckart KE, Donskey CJ. Evaluation of a hand-held far-ultraviolet radiation device for decontamination of Clostridium difficile and other health care associated pathogens. BMC Infect Dis 2012; 12(1): 120-25.

8. Melvin P, James S, April M. Clinical and Laboratory Standards Institute (CLSI) Performance standards for antimicrobial susceptibility testing: Twenty-ninth informational supplement. Document M100-S29. Wayne, PA: CLSI 2019. [Internet] Available at: https://clsi.org/media/3481/m100ed30_sample.pdf

9. Clinical and Laboratory Standards Institute. Reference Method for disk diffusion Antifungal Susceptibility Testing of Yeasts. document M44-A:Wayne, PA, CLSI; 2008 [Interent] Available at: https://clsi.org/media/1647/m51a_sample.pdf

10. Preparation of McFarland Turbidity Standards. [Interent] Available from: https://microbeonline.com/preparation-mcfarland-turbidity-standards/. [Accessed on 16 feb 2021].

11. Germicidal UV irradiation dosage table. [Internet] Available at: http//www.americanairandwater.com/uv-facts/uvdosage.html. [Accssed on 09 Dec 2020].

12. Li, Q, Med M, Guan X, Wu P, Wang X, Zhou L, et al. Early transmission dynamics in Wuhan, China, of novel coronavirus-infected pneumonia. N Engl J Med 2020; 382(1): 1197-07.

13. Lindblad M, Tano E, Lindhal C, Huss F. Ultra-C decontamination of a hospital room: Amount of UV light needed. Burns 2020; 46 (4): 842-49.

14. Boyce JM, Farrel PA, Towle D, Fekieta R, Aniskiewicz M. Impact of room location on UV-C irradiance and UV-C dosage and antimicrobial effect delivered by a mobile UV-C light device. Infect Control Hosp Epidemiol 2016; 37(6): 667-67.

15. Vázquez $M$, Hanslmeier A. Ultraviolet Radiation in the solar system. Springer; Dordrecht, The Netherlands: 2006. [Internet] Available at: https:/ / www.springer.com/gp/book/

16. 9781402037269.

17. Marra AR, Schweizer ML, Edmond MB. No-touch disinfection methods to decrease multidrug-resistant organism infections: a 
systematic review and meta-analysis. Infect Control Hosp Epidemiol 2018; 39(1): 20-31.

18. Bedell K, Buchaklian AH, Perlman S. Efficacy of an automated multiplier emitter whole-room Ultra violet- $C$ disinfection system against coronaviruses MHV and Mers Co V. Infect Control Hosp Epidemiol 2016; 37(5): 598-99.

19. Adebivi KS, Emeka-Ifebi A, Ogbonnaya MJ, Isekwene AC. Qualitative evaluation of the antimicrobial efficacy of UV sterilization chambers employed by barbershops in Benin City, Nigeria Adebiyi et al. Afr J Clin Exper Microbiol 2020; 21(3): 233- 39.

20. Katara G, Emvani N, Chitnis S, Chitnis V, Chitnis DS. Surface disinfection by exposure to germicidal UV light. Ind J Med Microbiol 2008; 26(3): 241-42.

21. Mahida N, Vaughan N, Boswell T. First UK evaluation of an automated ultraviolet $\mathrm{C}$ room decontamination device (Tru-D TM). J Hosp Infect 2013; 84(4): 332-35. 